\title{
Differential motor alterations in children with three types of attention deficit hyperactivity disorder
}

\author{
Alteraciones motoras diferenciales en niños con tres tipos de trastorno por déficit de \\ atención-hiperactividad
}

Adrián Poblano, Belinda Luna, César Reynoso

\begin{abstract}
Objective: To determine frequency of motor alterations in children with attention deficit hyperactivity disorder (ADHD). Method: We evaluated 19 children aged 7-12 years with ADHD classified in three sub-types: Combined (ADHD-C), with Inattention (ADHD-I), and with Hyperactivity (ADHD-H). Controls were age- and gender matched healthy children. We utilized Bruininks-Oseretsky Test of Motor Proficiency (BOTMP) for measuring motor skills. Results: We observed differences between children with ADHD and controls in BOTMP general score and in static coordination, dynamic general- and hand- coordination, and in synkinetic movements. We also found differences in dynamic hand coordination between controls and children with ADHD-C; in dynamic general coordination between controls and children with ADHD-H; and in frequency of synkinetic movements between controls and children with ADHD-H. Conclusion: Children with ADHD with a major degree of hyperactivity showed greater frequency of motor alterations.
\end{abstract}

Keywords: attention deficit disorder, motor development, inattention, hyperactivity, bruininks-oseretsky test.

\section{RESUMEN}

Objetivo: Determinar la frecuencia de alteraciones motoras en niños con trastorno por déficit de atención-hiperactividad (TDAH). Método: Evaluamos 19 niños de 7-12 años de edad con TDAH clasificados en tres subtipos: Combinado (TDAH-C), con Inatención (TDAH-I) y con Hiperactividad (TDAH-H). Los controles fueron niños sanos pareados por edad y género. Utilizamos la Prueba de eficiencia motora de Bruininks-Oseretsky (PEMBO). Resultados: Observamos diferencias entre los grupos de niños con TDAH en la calificación general de la PEMBO y en: coordinación estática, coordinación dinámica general, coordinación manual y en movimientos sincinéticos. También encontramos diferencias en la coordinación manual entre los controles y los niños con TDAH-C; en la coordinación dinámica general entre los controles y los niños con TDAH-H; y en la frecuencia de movimientos sincinéticos entre los controles y los niños con TDAH-H. Conclusión: Los niños con TDAH con una mayor grado de hiperactividad muestran una mayor frecuencia de alteraciones motoras y movimientos sincinéticos.

Palabras clave: trastorno por déficit de atención, desarrollo motor, inatención, hiperactividad, prueba de bruininks-oseretsky.

Attention deficit-hyperactivity disorder (ADHD) is an alteration that begins early in infancy and whose cardinal symptoms are inattention, hyperactivity, and impulsivity ${ }^{1,2}$. One of the main symptoms of ADHD in children is motor alterations manifested as restlessness and in other motor behaviors. For example, in one research, authors found differential distribution of motor alterations in children with ADHD with co-morbid developmental coordination disorder (DCD); children with ADHD predominantly inattentive, had significantly poorer fine motor skills while children with ADHD-combined type were found to experience significantly greater difficulty with gross motor skills ${ }^{3}$. These changes may be seasonal, the shortening photoperiods contribute to increasing diurnal and nocturnal agitation of children with $\mathrm{ADHD}^{4}$. However, there are yet few studies on the topic of motor disorders in subjects with $\mathrm{ADHD}^{5}$.

Some authors have proposed that ADHD comprises a broad group of mixed clinical categories, mainly groups with attention deficits only and those with a predominance of hyperactivity ${ }^{6,7}$. From this point of view, each subtype could have different neuropsychologic features. Thus, the objective of this research was to determine the frequency of motor

Laboratory of Cognitive Neurophysiology. National Institute of Rehabilitation, Mexico City, México.

Correspondence: Adrián Poblano; Calzada México-Xochimilco 289; 14389 México City, México; E-mail: drdislexia@yahoo.com.mx

Conflict of interest: There is no conflict of interest to declare.

Received 24 January 2014; Received in final form 19 July 2014; Accepted 07 August 2014. 
alterations in a group of children with $\mathrm{ADHD}$, with the working hypothesis that the percentage of motor alterations in children with ADHD with a major degree of hyperactivity, would be more than those without hyperactivity. On the other hand, as a secondary objective we sought to ascertain whether motor alterations correlate with other examinations, such as the scale for Evaluation of Deficit of Attention and Hyperactivity (EDAH).

\section{METHOD}

\section{Subjects}

We evaluated children aged 7-12 years who were students at a private or from public elementary schools who were referred as being suspected of ADHD by their school teachers. The children were examined by means of neurological, neuropsychiatric, neuropsychological, and electrophysiological tests. In case of acceptance, they were included in the Prospective Study of Children with ADHD of Mexico City (PSC-AD-HD-Mex). The diagnosis of ADHD was performed in agreement with recommendations of American Psychiatry Society guidelines ${ }^{8}$, in a three-step levels evaluation as follows; the first step was identification-at-school of children with a suspicion of ADHD by qualitative evaluation of teachers for their inattention and hyperactivity among the school population; the second was a screening conducted by means of the Diagnostic and Statistical Manual of Mental Disorders-IV-Text Revision (DSM-IV-R), and the scale of Evaluation Deficit of Attention and Hyperactivity (EDAH), searching for those children fulfilling criteria for inattentive and hyperactivity according to normative data; at last, the third step, comprised the semi-structured multidisciplinary interview by means of the Diagnostic Interview for Children and Adolescents (Chronbach's alpha score among interviewers of 0.65-1.00, and test-retest confidence values of $0.78-0.86)^{9}$, taking into account persistence of the disorder for a period $>6$ months of ADHD symptoms in at least two environments, such as school and home. The interview was performed by neurologist, psychiatrist, psychologist, and teachers-parents opinions ${ }^{2,10,11}$. We studied only children with intelligence quotients $>90$ (Wechsler intelligence scale for children). Children with $\mathrm{ADHD}$ were classified into the three recognized DSM-IV-R sub-types as follows: ADHD Combined (ADHD-C), mainly with Inattention symptoms (ADHD-I), and mainly with Hyperactivity-impulsivity (ADHD-H). All patients were medication-free until the conclusion of the initial assessment. Exclusion criteria were the following: co-morbidity of oppositional defiant disorder or conduct disorder; mental retardation; epilepsy; cerebral palsy; autism; blindness; deafness, and other neurological diseases. Anxiety, bipolar and coordination disorders were only searched in the case that child presented the symptoms that suggests the alteration. We rejected also children who were previously tested within the last 6 months with the same neuropsychological tests that we employed in this research. We constructed a control group of age- and gender matched healthy asymptomatic children from the same schools. Control children were similar in academic grade and had a similar socio-economic background without ADHD. Comparison of intelligence quotients showed not differences with children with ADHD. Children with ADHD and control subjects were studied in a blind fashion to avoid any bias. Sample size was calculated by standard deviation obtained after Piek et al., in the Motor assessment battery for children in 9 children per group (ADHD and controls) with a beta power of $80 \%{ }^{12}$. Parents and children were widely informed about the study and the importance of their participation in it. This investigation was approved by the Research and Ethics Committee of the National Institute of Rehabilitation (Mexico City), and informed consent was signed by the parents of participating children.

\section{Bruininks-Oseretsky Test of Motor Proficiency}

We utilized the Bruininks-Oseretsky Test of Motor Proficiency (BOTMP) as the instrument for measuring motor skills $^{13}$. The BOTMP is a standardized assessment of motor skills achievement commonly utilized in the assessment of motor abilities in children. The BOTMP has been validated in Spanish ${ }^{14}$ and consists of several items in five sub-tests. These sub-tests including the following: static coordination; dynamic hand coordination; dynamic general coordination; speed of movements; simultaneous movements, and presence of synkinetic movements. BOTMP possesses a whole general score and others scores for each sub-test measurements that were adjusted for child's age and gender. Score was employed to interpret test performance.

\section{EDAH}

We administered the scale for Evaluation for Deficit in Attention and Hyperactivity (EDAH) in teachers and parents of the population of children in our sample ${ }^{11,15}$. The questionnaire affords a structured observation of 20 items that are divided into the following two 10-item sub-scales: (1) subscale for attention deficit-hyperactivity disorder, and (2) sub-scale for conduct disorder (CD). When a certain child complies with the criteria, he/she can be categorized as being suspected of having ADHD. Questions can be answered in four ways with the following numerical equivalences: "never" = 0; "sometimes" = 1 ; "often" = 2, and "very often" $=3$.

\section{Statistical analysis}

We measured the mean and SD of continuous variables and percentages in binomial variables. We utilized the 
Student $t$-test to compare means between groups. We used a one-way Analysis of Variance (ANOVA) to compare the means of each ADHD type with control children. The Tukey Honestly significant differences (HSD) test was utilized to find differences between groups. We employed the calculation of the correlation between BOTMP and EDAH scores by means of the Spearman method. The a-priori alpha value accepted was $p \leq 0.05$. We utilized SPPS software version 17.0.

\section{RESULTS}

The sample was of 19 children with ADHD, and 19 control children. Both groups had a median age of 10 years. In both groups 16 children were masculine (84\%) and three, feminine (16\%). In the group of children with $\mathrm{ADHD}$, five children were in the ADHD-I (26\%) group, five were in the $\mathrm{ADHD}-\mathrm{H}$ (26\%) group, and nine were in the ADHD-C (47\%) group.

In overall, children diagnosed with $\mathrm{ADHD}$ achieved lower scores than those of control children in all BOTMP sub-tests. The general score of the BOTMP test in control children was $328.94 \pm 71.72$, while that of children with ADHD was $215.89 \pm 69.94(t=4.87 ; p<0.001)$. The results of each sub-test can be seen in Table. This table depicts significant differences in static coordination, dynamic hand coordination, dynamic general coordination, and frequency of synkinetic movements.

One-way ANOVA analysis detected differences in BOTMP between control children and children with $\mathrm{ADHD}$ in each type as follows: BOTMP general score $(\mathrm{F}=7.47 ; \mathrm{df}=3,33 ; \mathrm{p}=0.001)$, Tukey HSD found that there were differences between control children and children with $\mathrm{AD}-\mathrm{HD}$ of the three groups; dynamic hand coordination ( $F=6.06$; $d f=3,34 ; p=0.002)$, Tukey HSD exhibited differences between control children and children with ADHD-C; dynamic general coordination $(\mathrm{F}=3.64 ; \mathrm{df}=3,34 ; \mathrm{p}=0.02)$, Tukey HSD found differences between control children and children with $\mathrm{ADHD}-\mathrm{H}$; frequency of synkinetic movements $(F=3.20 ; d f=3,34 ; p=0.03$ ), Tukey HSD also found differences between control children and children with ADHD-H.
We disclosed a positive correlation only between the frequency of the synkinetic movements score in BOTMP and EDAH teachers score $(r=0.76 ; p=0.004)$.

\section{DISCUSSION}

\section{Main findings}

As expected from antecedents in literature, we disclosed that our children with ADHD showed a major frequency of motor alterations when they were compared with a group of control children. The main alterations were observed in the following BOTMP subtests: static coordination; dynamic hand coordination, dynamic general coordination, and in synkinetic movements. We must underline, that as predicted in our working hypothesis, children with ADHD subtypes with hyperactivity (ADHD-H and ADHD-C) demonstrated a significantly greater frequency of motor alterations than children with ADHD-I without hyperactivity. This result highlights our working hypothesis, that children with ADHD with hyperactivity exhibit different neuropsychological features than children with only inattentive symptoms. However it is difficult to make statements about coordination alteration and ADHD subtype yet. Finally, we discovered a positive correlation between synkinetic movement score in BOTMP with the EDAH teachers' score.

Our results underline the clinical relevance of motor alteration in children with ADHD. Thus, clinicians must ask for alterations in specific motor behaviors (static coordination; dynamic hand and general coordination, and presence of synkinetic movements) to teachers and parents of children with ADHD. Data reported here, and from other groups could be a guide to the questions for these movement disorders. On the other hand, our results confirm the clinical observation, that children with ADHD with hyperactivity have more motor alterations, than those children with $\mathrm{ADHD}$ with attention deficit only. This finding suggest, that hyperactivity disorder must engage different neural networks alteration that attention deficit only, as will be discussed below. Correlation among frequency of synkinetic movements and teachers' EDAH scores may means that teachers are more sensitive to detect abnormal

Table. Results of Bruininks-Oseretsky Test of Motor Proficiency in Control and children with Attention deficit hyperactivity disorder.

\begin{tabular}{|c|c|c|c|c|c|c|}
\hline & $\begin{array}{c}\text { Static } \\
\text { coordination }\end{array}$ & $\begin{array}{l}\text { Dynamic hand } \\
\text { coordination }\end{array}$ & $\begin{array}{l}\text { Dynamic general } \\
\text { coordination }\end{array}$ & $\begin{array}{l}\text { Speed of } \\
\text { movements }\end{array}$ & $\begin{array}{l}\text { Simultaneous } \\
\text { movements }\end{array}$ & $\begin{array}{l}\text { Synkinetic } \\
\text { movements }\end{array}$ \\
\hline Controls & $58.98 \pm 37.43$ & $61.05 \pm 29.43$ & $68.94 \pm 26.78$ & $38.15 \pm 21.02$ & $51.15 \pm 20.82$ & $55.94 \pm 26.39$ \\
\hline $\begin{array}{l}\text { Children with } \\
\text { ADHD }\end{array}$ & $35.84 \pm 25.71$ & $30.42 \pm 13.01$ & $44.57 \pm 27.45$ & $26.78 \pm 16.90$ & $39.63 \pm 16.94$ & $33.36 \pm 19.71$ \\
\hline t & 2.03 & 4.14 & 3.02 & 1.83 & 1.87 & 2.98 \\
\hline$p$ & 0.02 & $<0.001$ & 0.005 & $0.07^{\mathrm{ns}}$ & $0.06^{\text {ns }}$ & 0.005 \\
\hline
\end{tabular}

Values represent the average of the scores \pm the Standard deviation (SD) of each sub-test; BOTMP: Bruininks-Oseretsky Test of Motor Proficiency; ADHD: Attention deficit hyperactivity disorder; ns: Not significant. 
movements than parents, because they have opportunity to compare motor behavior in more children. If gender has influence on motor impairment in children with ADHD, it is an interesting question, but we studied few female subjects to make inferences on this effect, this fact deserve more attention in future research.

\section{Comparison with other studies}

Pitcher et al. published three papers about motor alterations present in male children with $\mathrm{ADHD}^{3,16,17}$. Comparison with our results must be made with caution due to differences in methodology and in type of subjects studied. However, in overall, author's results are in line with our data. In the first investigation, the authors found differential distribution of motor alterations in children with ADHD with comorbid developmental coordination disorder (DCD). Children with ADHD-I had significantly poorer fine motor skills, while children with ADHD-C were found to experience greater difficulty with gross motor skills. The severity of the children's with inattentive symptoms was found to be a significant predictor of motor coordination difficulties ${ }^{3}$. In the second research, investigators found that boys with subtypes that included inattentive symptomatology had significant difficulties with timing and force control; and showed greater variability in motor outcomes; boys with DCD had particular difficulty with force control ${ }^{16}$. In partial agreement with our results, the authors identified a need for increased recognition of relationship between ADHD and motor dysfunction, and found that type and degree of movement difficulty differed among $\mathrm{ADHD}$ subtypes. In the third research, authors found that males with ADHD-I and ADHD-C had significantly poorer fine motor ability than control children. Because children with ADHD only, and those of the control group did not differ significantly in terms of fine motor ability but were significantly better than children categorized with both ADHD and DCD, researchers suggested that the poorer fine motor ability found in children with ADHD could not be attributed to deficits in attention and concentration, but rather to factors relating to their motor ability ${ }^{17}$. In overall, the main differences between these investigations and our study comprise the presence of comorbid DCD, thus, we think that the children in their studies had a more severe degree of alteration in the motor domain; and that the different scale employed from ours to study motor function development limits comparisons.

In other paper, motor development assessment of school children with $\mathrm{ADHD}$ was studied in a sample of children aged 7-10 years. Investigators found that $48 \%$ of children with $\mathrm{ADHD}$ were in the low range of motor performance according to a Scale of Motor Development ${ }^{18}$. In other research, motor development was reported again as normal, but in a lower range, in children with $\mathrm{ADHD}$ in a sample of 846 children from 5-12 years of age according to a Battery of
Psychomotor Observation ${ }^{19}$. Authors of these studies did not find a clear disadvantage of children with $\mathrm{ADHD}$ vs. control children when these were compared regarding motor behaviors. Comparison with our data is again difficult, because of different objectives and study methods, but in general they are in partial agreement with our data showing the low motor performance of children with ADHD.

One study on the motor performance of subjects with ADHD was conducted in adults. In this paper, an infrared motion-tracking system was employed to measure motor activity in 20 free-of-medication adults with ADHD and 20 matched controls during a one-back working memory task. Motor activity was higher in adults with ADHD, and increased over the duration of testing and co-varied with cognitive performance in ADHD only ${ }^{5}$. Although this work showed differences in motor behavior in adults with ADHD vs. healthy controls, we are unable to formulated additional considerations due to differences in age and methodologies between studies.

Barbosa-Goulardins et al. ${ }^{20}$, studied the relationship between motor alterations and quality of life (QoL) in children with ADHD. These authors demonstrated the adverse effects of ADHD in QoL and in motor skills. Nine of their participants $(64.2 \%)$ were classified in motor development as: "normal medium", followed by the classification of "normal low" in four (28.5\%), and "low" in one subject $(7.1 \%)$. These authors observed a positive correlation between QoL and the psychomotor development of children with $\mathrm{ADHD}$ in the following areas: fine motor and spatial organization with social and psychosocial aspects; gross motor control with emotional aspects, and temporal organization with the emotional, psychosocial, and in overall, with QoL. Their results are in line with our data reported here and with those we found in other observation that disclosed a low QoL in children with ADHD is related with anxiety levels $^{21}$. Comparison are limited by the test used to study motor behavior. We used BOTMP because the test is of wide use in our country and was standardized for use in latino-communities.

We observed a significant correlation between synkinetic movements score in BOTMP and the EDAH score of the teachers' scale. These results are in line with other researchers found a correlation between EDAH scores and other ADHD tests, such as Urzua et al. ${ }^{22}$, and Zambrano-Sánchez et al. ${ }^{11}$. However, to our knowledge, few studies have been performed before to correlate EDAH with another psychometric test, as we did.

Alterations in dopaminergic activity has been related to abnormal motor behavior in children with ADHD. Other condition in which abnormal dopaminergic activity is the periodic limb movements in sleep (PLMS). The symptoms of PLMS in motor sleep behavior in children are similar to those of motor restless in awake children with ADHD. 
Both disorders are related with dopamine production and metabolism, and both respond to dopaminergic therapy ${ }^{23}$. The co-existence of ADHD and PLMS is reported to occur with a certain frequency ${ }^{24}$.

Symptoms in children with ADHD include hyperactivity, distractibility during task performance, disorganization, inability to follow through on a plan, inability to shift set and reprogram activities when needed, and deficient rulegoverning behavior. These symptoms have been associated with abnormalities of the frontal lobe systems, particularly: executive systems ${ }^{10}$. The frontal systems are part of a broad network with connections to nearly all parts of the central nervous system (CNS). Therefore, possibly all cognitive systems are sensitive to frontal lobe pathology, i.e., $\mathrm{ADHD}^{25}$. The involvement of executive control includes, for instance, the ability to command motor exploration, to monitor and shift the direction of attention, to initiate and direct language, to organize methods of memorization, to temporally discriminate items in memory, and to inhibit interference during recall ${ }^{26}$.

Recently, Langevin et al. ${ }^{4}$ found by means of MRI by diffusion tension images that some alterations in the Corpus callosum may underlie the difficulties in motor and attention functioning in children with $\mathrm{ADHD}$ and developmental motor disorder. In a second paper, Langevin and Ramdé showed that these changes may be seasonal, and shortening photoperiods contribute to increase the diurnal and nocturnal agitation of children with ADHD, and that lengthening diminish $\mathrm{it}^{27}$. Results from the above quoted research, support our data showing the possible pathophysiological basis of the motor alterations. Thus, we suggest that the motor alterations must be systematically examined in children with $\mathrm{ADHD}$ in future studies.

\section{Study limitations}

Our study has some limitations. In first place, the number of children studied is small, therefore, our results must be considered as tendencies and not as strong conclusions. The study design was a cross-sectional observation; in the future, we must design a prospective long-term follow-up observations including other co-variables that may influence motor development. Finally, our study lacks dynamic neuroimaging correlation ${ }^{28}$. Thus, in the subsequent research, we must include functional magnetic resonance imaging studies to support our observations.

\section{CONCLUSION}

We must highlight that children with $\mathrm{ADHD}$ exhibited a greater frequency of motor alterations than control children. The main alterations were observed in: static coordination, dynamic hand coordination, dynamic general coordination, and in synkinetic movements. Finally, the synkinetic movements score in BOTMP correlates well with the EDAH teachers' scale score. We propose than in the future these alterations should be related to functional neuroimaging studies.

\section{References}

1. Dupaul GJ, Mc Goey KE, Eckert TL, Brankle J. Preschool children with attention-deficit/hyperactivity disorder: impairments in behavioral, social, and school functioning. J Am Acad Child Adolesc Psychiatry. 2001;40(5):508-15. http://dx.doi.org/10.1097/00004583-20010500000009

2. Poblano A, Romero E. ECl-4 screening of attention deficithyperactivity disorder and co-morbidity in Mexican preschool children. Preliminary results. Arq Neuropsiquiatr. 2006;64(4):932-6. http://dx.doi.org/10.1590/s0004-282×2006000600008

3. Piek JP, Pitcher TM, Hay DA. Motor coordination and kinaesthesis in boys with attention deficit-hyperactivity disorder. Dev Med Child Neurol. 1999;41(3):159-65. http://dx.doi.org/10.1017/s0012162299000341

4. Langevin R, Ramdé J. Attention deficit hyperactivity disorder (ADHD) in children, seasonal photoperiods, nocturnal movements and diurnal agitation. J Can Acad Child Adolsc Psychiatry. 2012;21(1):53-8.

5. Lis S, Baer N, Stein-en-Nosse C, Gallhofer B, Sammer G, Kirsch P. Objective measurement of motor activity during cognitive performance in adults with attention-deficit/hyperactivity disorder. Acta Psychiatr Scand. 2010;122(4):285-94. http://dx.doi.org/10.1111/ j.1600-0447.2010.01549.x

6. Coghill D, Seth S. Do the diagnostic criteria for ADHD need to change? Comments on the preliminary proposals of the DSM-5 ADHD and Disruptive Behavior Disorders Committee. Eur Child Adolesc Psychiatry. 2011;20(2):75-81. http://dx.doi.org/10.1007/s00787-010-0142-4
Solanto MV, Gilbert SN, Raj A, Zhu J, Pope-Boyd S, Stepak B et al. Neurocognitive functioning in AD/HD, predominantly inattentive and combined subtypes. J Abnorm Child Psychol. 2007;35(5):729-44. http://dx.doi.org/10.1007/s10802-007-9123-6

8. American Psychiatric Association. Diagnostic and statistical manual of mental disorders (DSM-IV). 4thedition. Washington: American Psychiatric Association; 1994.

9. Angold A, Erkanli A, Copeland W, Goodman R, Fisher PW, Costello EJ. Psychiatric diagnostic interviews for children and adolescents: a comparative study. J Am Acad Child Adolesc Psychiatry. 2012;51(5):506-17. http://dx.doi.org/10.1016/j.jaac.2012.02.020

10. Zambrano-Sánchez E, Martínez-Cortés JA, del Río-Carlos Y, Martínez-Wbaldo MC, Poblano A. Executive dysfunction screening and intellectual coefficient measurement in children with attention deficit-hyperactivity disorder. Arq Neuropsiquiatr. 2010;68(4):545-9. http://dx.doi.org/10.1590/s0004-282x2010000400013

11. Zambrano-Sánchez E, Martínez-Cortés JA, Río-Carlos Y, MartínezWbaldo MC, Poblano A. Identification of attention deficit hyperactivity disorder and conduct disorder in Mexican children by the scale of evaluation of deficit of attention and hyperactivity. Psychiatry Res. 2011;187(3):437-40. http://dx.doi.org/10.1016/j.psychres.2010.09.004

12. García-García JA, Reding-Bernal A, López-Alvarenga JC. Sample size calculation in medical education research [Spanish]. Inv Ed Med. 2013;2(8):217-24. 
13. Wilson BN, Polatajko HJ, Kaplan BJ, Faris P. Use of BruininksOseretsky test of motor proficiency in occupational therapy. Am J Occup Ther 1995;49(1):8-17. http://dx.doi.org/10.5014/ajot.49.1.8

14. Lozoff B, Jiménez E, Wolf AW. Long-term developmental outcome of infants with iron deficiency. New Engl J Med 1991;325(10):687-94. http://dx.doi.org/10.1056/NEJM199109053251004

15. Farre-Riba A, Narbona-García J. EDAH. Scales for evaluation of deficit of attention and hyperactivity [Spanish]. Madrid: Publicaciones de Psicología Aplicada; 2001.

16. Pitcher TM, Piek JP, Barrett NC. Time and force control in boys with attention deficit hyperactivity disorder: subtype differences and the effect of co-morbid developmental coordination disorder. Hum Mov Sci. 2002;21(5-6):919-45. http://dx.doi.org/10.1016/s0167-9457(02) 00167-7

17. Pitcher TM, Piek JP, Hay DA. Fine and gross motor ability in males with ADHD. Dev Med Child Neurol. 2003;45(8):525-35. http://dx.doi. org/10.1017/s0012162203000975

18. Poeta LS, Rosa-Neto F. Motor assessment in school aged children with indicators of the attention deficit/hyperactivity disorder [Spanish]. Rev Neurol. 2007;44(3):146-9. http://dx.doi.org/10.1385/159259-891-9:143

19. Vidarte JA, Ezquerro M, Girádez MA. Psychomotor profile of children between 5 and 2 years of age, clinically diagnosed with attention deficit hyperactivity disorder in Colombia [Spanish]. Rev Neurol. 2009;49(2):69-75.

20. Goulardins JB, Bilhar JCF, Marques JC, Casella EB. Quality of life and psychomotor profile of children with attention deficit hyperactivity disorder (ADHD). Arq Neuropsiquiat. 2011;69(4):630-5. http://dx.doi. org/10.1590/s0004-282×2011000500011

21. Zambrano Sánchez E, Martínez Cortés JA, Río Carlos Y, Dehesa Moreno M, Poblano A. Low quality of life scores in school children with attention deficit-hyperactivity disorder are anxiety-related. Arq Neuropsiquiatr. 2012;70(3):180-4. http://dx.doi.org/10.1590/S0004282X2012000300005

22. Urzúa A, Domic M, Ramos M, Cerda A, Quiroz J. Psychometric properties of three rating scales for attention deficit hyperactivity disorder in Chilean students [Spanish]. Rev Panam Salud Publica. 2010;27(3):157-67. http://dx.doi.org/10.1590/S102049892010000300002

23. Pockett C, Kirk V. Periodic limb movements in sleep and attention deficit hyperactivity disorder: are they related? Paediatr Child Health. 2006;11(6):355-8.

24. Zambrano Sánchez E, Martínez Cortés JA, Dehesa Moreno M, Río Carlos Y, Poblano A. Correlation between sleep disorders screening and executive dysfunction in children with attention deficit-hyperactivity disorder. Arq Neuropsiquiatr. 2013;71(11):896-901. http://dx. doi.org/10.1590/0004-282×20130174

25. Lazar JW, Frank Y. Frontal systems dysfunction in children with attention-deficit/hyperactivity disorder and learning disabilities. J Neuropsychiatr Clinical Neurosci 1998;10(2):160-7.

26. Mulligan RC, Knopik VS, Sweet LH, Fischer M, Seidenberg M, Rao SM. Neural correlates of inhibitory control in adult attention deficit/ hyperactivity disorder: evidence from the Milwaukee longitudinal sample. Psychiatry Res. 2011;194(2):119-29. http://dx.doi.org/ 10.1016/j.pscychresns.2011.02.003

27. Langevin LM, MacMaster FP, Crawford S, Lebel C, Dewey D. Common white matter microstructure alterations in pediatric motor and attention disorders. J Pediatr. 2014;164(5):1157-64. http://dx.doi. org/10.1016/j.jpeds.2014.01.018

28. Shaw P, Rabin C. New insights into attention-deficit/hyperactivity disorder using structural neuroimaging. Curr Psychiatry Rep. 2009;11(5):393-8. http://dx.doi.org/10.1007/s11920-009-0059-0 